\title{
POLITICAS INDIGENISTAS E MOVIMENTOS INDÍGENAS NO BRASIL
}

\author{
Indigenist politics and indigenous movements in Brazil
}

\section{ALINA CELARIÉ* \& MAXIM REPETTO**}

\author{
Fecha de recepción: 24 de agosto de 2020 - Fecha de aprobación: 30 de noviembre de 2020
}

\section{Resumo}

No presente artigo, analisaremos as políticas indigenistas brasileiras no século $\mathrm{XX}$ e o surgimento dos movimentos indígenas a partir dos anos de 1970. Queremos mostrar uma visão geral desse panorama histórico, ressaltar as definições principais das políticas indigenistas e sua articulação com o indigenismo interamericano, assim como as rupturas surgidas em parte pelos questionamentos do movimento indígena e pela constituição de 1980. Veremos a passagem de políticas indigenistas tutelares e de controle desses povos, para uma crescente atuação e mobilização indígena, ancorada na defesa da terra, assim como de outras reivindicações importantes, como a melhoria do atendimento à saúde e à educação. Identificaremos, desse modo, os principais conceitos e os avanços nessa luta, que como pano de fundo questionam o exercício dos direitos e nos falam da ampliação do conceito de cidadania no contexto atual dos Estados Nacionais na América Latina.

Palavras chave: Movimentos indígenas; Políticas indigenistas, Povos indígenas no Brasil.

\begin{abstract}
In this article, we will analyze the Brazilian indigenist policy in the 20th century and the rise of indigenous movements from the 1970s. We want to show an overview of this historical panorama, highlighting the main definitions of indigenist policies and their articulation with Inter-American indigenism. Furthermore, we will discuss the ruptures that arose from the questioning of the indigenous movement and the constitution of 1980 . We will see the transition from tutelary indigenist policies and peoples control, to a growing performance and indigenous mobilization. This mobilization is based on the defense of the land, as well as other important claims, such as, improvements in health care and education. Finally, we will identify the main concepts and progresses in this fight. Knowing that the backstory of this progresses questions the exercise of rights and tells us about the expansion of the concept of citizenship in the current context of National States in Latin America.
\end{abstract}

Keywords: Indigenous movements; Indigenist policies, Indigenous peoples in Brazil.

\footnotetext{
* Mestre pelo Programa de Pós-Graduação em Sociedade e Fronteiras (PPGSOF), Universidade Federal de Roraima, Brasil. Correo-e: alina.celarie@gmail.com

** Dr. Antropologia Social. Professor do Programa de Pós-Graduação em Sociedade e Fronteiras (PPGSOF), Curso Licenciatura Intercultural, Instituto Insikiran de Formação Superior Indígena - Universidade Federal de Roraima, Brasil. Correo-e: maxim.repetto@yahoo.com.br
} 


\section{Introdução}

O presente artigo trata sobre uma pesquisa desenvolvida no contexto do Programa de pós-graduação em Sociedade e Fronteiras (PPGSOF), na Universidade Federal de Roraima, Brasil (Celarié Iglesias, 2016) a qual tratou sobre o movimento indígena no Brasil e as lutas para concretizar novos sentidos para o exercício de direitos dos povos indígenas. Nesse sentido articula uma análise das políticas indigenistas no Brasil, em contraste com as lutas dos movimentos indígenas na busca de ampliar o exercício da cidadania.

A base do presente trabalho foi uma pesquisa bibliográfica e de campo junto de lideranças indígenas e teve como foco de reflexão os debates sobre Estados Nacionais e cidadanias diferenciadas. Apresentamos aqui uma parte desse trabalho, no intuito de divulgar a luta dos povos indígenas no Brasil e assim promover uma reflexão sobre os desafios que enfrentam os Estados nacionais na consolidação dos processos democráticos no continente latino-americano.

Nesse sentido a história do Brasil indígena está marcada por diferentes processos políticos e sociais que envolvem situações e relações complexas entre os indígenas e os não indígenas. A história do período colonial, imperial e republicano se encontram relacionadas sob eixos indigenistas marcantes, sempre tentando absorver às diferenças culturais e enquadrá-las num cenário "novo" e etnocêntrico. Portanto, é importante entender e revisar rapidamente como é que dentro desses processos os povos indígenas estiveram num campo cheio de contextos conflitivos, discriminatórios e assimilacionistas.
No século $X X$, as instituições políticas no Brasil estabeleceram formas de poder totalizantes sobre os povos indígenas, impondo invisibilidade, submissão, clientelismo, paternalismo, dependência e uma série de ideias voltadas para lidar, administrar e absorver os indígenas dentro da sociedade nacional. Apesar de ter projetos civilizatórios, de catequese e de integração, nem sempre a invisibilidade e a sujeição do indígena permaneceram. Os povos indígenas do Brasil, ao tomar consciência histórica, ao se organizarem e reclamar seu direito e reconhecimento como comunidades culturais e políticas e com territórios próprios, permearam dentro do Brasil novos caminhos de incidência para exercer sua cidadania e reivindicar direitos.

\section{O indigenismo e o poder tutelar}

A partir da colonização, Portugal e o Brasil progressivamente foram impondo controle territorial, de conhecimentos, cultural e até corporal. As populações indígenas foram vistas como um obstáculo a mais e até como um instrumento de ajuda e de sujeição para o desenvolvimento colonial e imperial.

A nossa história tem sido sempre descrita como a história da colonização, como a narrativa da transferência de pessoas, instituições e conhecimentos para um novo cenário, não-europeu, sobre o qual estas vieram a estabelecer um progressivo controle, dando origem ao marco territorial atual. Nesse relato as populações autóctones entraram sobretudo marcadas pelo acidental, pelo exótico e pelo passageiro, como se a existência de indígenas fosse algo inteiramente fortuito, um obstáculo que logo veio a ser superado e, com o passar do tempo, chegou a ser minimizado e quase inteiramente esquecido (Pacheco de oliveira \& Rocha freire, 2006, p. 17). 
Dentro da perspectiva de sujeição e de invisibilidade do indígena, colocado como fosse algo esquecido ou como algo em vias de extinção, ou do passado, temos que considerar que a sociedade brasileira não pode ser compreendida sem as populações indígenas (Pacheco de oliveira \& Rocha freire, 2006). Apesar de ser uma minoria em relação à sociedade nacional, os indígenas inseriram-se no imaginário nacional "indeed, although they are a tiny minoritywith the possible exception of Argentina's, the Brazilian Indians are the smallest indigenous population in the Americas- they have the power to surrow deeply into the country's imagination." (Ramos, 1998, p. 3).

As diversas modalidades de dominação marcadas desde a colonização, onde populações foram destruídas e submetidas através da guerra ou através de variados sistemas e modos de dominação hegemonizados pelo conquistador, passaram a ser objeto do poder tutelar. (Lima, 1995)

O Estado e as diferentes empresas colonizadoras têm procurado representar e administrar os povos indígenas para a sua conveniência, deixando muitas vezes de fora as vozes e as demandas das populações indígenas. Para entender o estabelecimento das políticas destinadas aos povos indígenas, podemos revisar o campo das relações políticas que se estabelecem entre os índios e os brasileiros, e que é chamado de indigenismo.

The political field of relations betweem Brazilians and Indians-call it contact zone, middle grounds, or colonial situation-acquires in Brazil a magnitude that is not explained by a single cause, such as competition for material and symbolic resources. Rather, this field that $i$ call Indigenism is the result of many overlapping factors that history has compunded in an extraordinary case of collective overdetermintation. (Ramos, 1998, p. 5)
O termo indigenismo estabelece-se na produção literária latino-americana e designou-se, de início, como uma corrente de pensamento, mas seria no campo político mexicano que o significado do indigenismo ganharia estabilidade a partir da Revolução de 1910 e ganharia mais espaço com a instauração do chamado indigenismo interamericano em Patzcuaro, em 1940.

Como definição operativa pode-se considerar o indigenismo como

O conjunto de ideias (e ideais, aquelas elevadas à qualidade de metas a serem atingidas em termos práticos) relativas à inserção de povos indígenas em sociedades subsumidas a Estados nacionais, com ênfase especial na formulação de métodos para o tratamento das populações nativas, operados, em especial, segundo uma definição do que seja índio. (Lima, 1995, p. 15)

O enquadramento do indigenismo, como base de um pensamento protetor e de absorção, encontra sua estratégia e sua ação nas políticas indigenistas, com as quais se designam as medidas práticas formuladas por distintos poderes direta ou indiretamente sobre os povos indígenas (Lima, 1995).

Vale ressaltar que o indigenismo, assim como as políticas indigenistas, surgem do Estado e suas instituições. O Estado pode ser considerado como aquele que concentra a preservação do poder e como aquela instituição ou conjunto de instituições especificamente relacionadas com a conservação da ordem.

La discusión acerca del estado puede iniciarse con la célebre definición que Max Weber diera de él, como el agente que detenta el monopolio de la violencia legítima dentro de la sociedad. La idea que subyace bajo esta definición es sencilla y atractiva: en las sociedades plenamente organizadas, como la mayoría de aquellas en que vivimos o deseamos vivir, la violencia particular o sectorial es ilegítima. El conflicto como tal no lo 
es, pero no puede resolverse de forma lícita mediante aquélla. Sólo puede hacer uso de la violencia la autoridad política central y aquellos en quien delega este derecho. De entre las varias formas autorizadas de mantener el orden, la última —la fuerza - sólo puede ser utilizada dentro de la sociedad por un agente especial, claramente identificado, fuertemente centralizado y disciplinado. Ese agente o conjunto de agentes es el estado. (Gellner, 1988, p. 16)

A ideia de que o Estado, através da centralização de diferentes técnicas de poder, totaliza e integra, encontra seu fundamento no período do final do século XIX e as primeiras décadas do século XX no Brasil, onde aconteceu um delineamento de um formato sócio-político à definição básica de seus limites internacionais e expansão sobre o espaço geográfico e esse modo de relacionamento e governamentalização de poderes foi concebido para coincidir com uma única nação e é sob esse eixo que se denomina e se instaura o poder tutelar (Lima, 1995).

Ressalta-se a ação do Estado que pretendia abarcar e submeter a multiplicidade de comunidades étnicas diferenciadas; o poder tutelar encontrava seu poder num aparelho de abrangência nacional. Nesse sentido, o poder tutelar encontraria sua ação e abrangência por meio de uma agência para a proteção dos indígenas, assim a criação do Serviço de Proteção aos Índios (SPI), em 1910, estabeleceu-se como o administrador e disciplinador dos indígenas.

In 1910 the first national agency for the protection of the Indians was created by an army officer, Cândido Mariano da Silva Rondon, a true believer in positivismo as a humanista philosophy. Faithful to the Comtean version of evolution, he was convinced of the need to preserve the lives of indigenous peoples so that they could ultimately decide to abandon their primitive ways and embrace Western civilization. As civilizing strategy, Rondon applied some army devices, such as furnishing titles and olive uniforms to Indian men who often had no local legitimacy. It was the modern period of the village "captains". Official indigenismo was thus created, and the destiny of the Indians was sealed: slowly but surely, they were to relinquish their lifeways and integrate into national society. (Ramos, 1998, p. 80)

Nesse sentido, Rondon revelava uma imagem do índio que aguardava a intervenção salvadora do governo. A nova política indigenista assentou-se na experiência de Rondon. Assim, o regime tutelar deu-se com o SPI (Serviço de Proteção aos Índios) que foi a primeira agência do Estado brasileiro a gerenciar povos indígenas.

A ação indigenista teria por finalidades: a) estabelecer a convivência pacífica com os índios; b) agir para garantir a sobrevivência física dos povos indígenas; c) fazer os índios adotarem gradualmente hábitos "civilizados"; d) influir de forma "amistosa" sobre a vida indígena; e) fixar o índio à terra; f) contribuir para o povoamento do interior do Brasil; g) poder acessar ou produzir bens econômicos nas terras dos índios; h) usar a força de trabalho indígena para aumentar a produtividade agrícola; i) fortalecer o sentimento indígena de pertencer a uma nação. (Pacheco de oliveira \& Rocha freire, 2006, pp. 112-113)

Para a administração do poder tutelar, o importante era rotular genericamente as populações e inseri-las num sistema de atribuições positivas e negativas. O indígena como categoria serviu de incidência para práticas e representações governamentalizadas e jurídicas.

Trata-se aqui de assumir como viés interpretativo que o poder tutelar é uma forma reelaborada de uma guerra, ou, de maneira muito mais especifica, do que se pode construir como um modelo formal de uma das formas de relacionamentos possível entre um "eu" e um "outro" afastados por uma alteridade (econômica, política, simbólica e espacial) radical, isto é, a conquista, cujos 
princípios primeiros se repetem- como toda a repetição, de forma diferenciada- a cada pacificação. (Lima, 1995, p. 43)

Sendo assim, o que atribui o significado ao poder tutelar dá-se no modo da complexidade dos diferentes relacionamentos e atitudes tomadas com os povos indígenas. Se por um lado existia uma mediação sem entrar em disputas, por outro lado era benéfico aproveitarse do próprio conflito.

É interessante observar como o poder tutelar, dentro de seu caráter jurídico, tinha como fim legitimar e universalizar a própria administração sobre as populações indígenas sobre as quais incidia-se. Contradizia-se, então, a forma de querer ampliar a relação entre o Estado e a cidadania tentando abrir a participação política para o indígena, já que muitas vezes resultava e apontava na direção oposta.

Se a literatura especializada tem apontado a relação entre Estado nacional e expansão da cidadania- notadamente sob os aspectos de um acesso mais amplo por parte de certas classes e frações de classe aos direitos civis (sobretudo os sociais) e a uma suposta maior participação política-, a forma como é concebida a inserção dos indígenas na "comunidade política brasileira" aponta em direção muito distinta e oposta (Lima, 1995, p. 75).

É interessante ressaltar que ao longo dos anos 1950, dentro da ação indigenista do SPI, somaram-se visões por parte de profissionais que estiveram envolvidos com as questões da antropologia cultural e social, com o mundo do pós-guerra e com a crítica dos nacionalismos e colonialismos que marcaram o século $X X$, revelando-se nas descolonizações. Etnólogos do SPI,
Viram surgir a Declaração Universal de Direitos do Homem, de 10/12/1948, dos quais também redundaria a Convenção n.․ 107, de 26 de junho de 1957, da Organização Internacional para o Trabalho (OIT), sobre a Proteção de Populações Indígenas e Tribais, de cujo processo de discussão participou o SPI. (Lima, 2005, p. 243)

Nesse sentido, surgiria a ideia de que as terras ocupadas pelos indígenas deveriam Ihes assegurar uma transformação social e paulatina.

Disso surgiu a proposição e posterior criação de três parques indígenas, dos quais o mais conhecido é o do Xingu (hoje chamado terra indígena), regulamentados após muita luta, por Jânio Quadros, em 1961. Extensões de terras muito maiores suscitaram inúmeras oposições, sobretudo dos que se articulavam com a "indústria" de grilagem de terras na região de Mato Grosso e Goiás. (Lima, 2005, p. 243)

A dinâmica tutelar encontrou o seu maior produto nas reservas indígenas, a possibilidade do reconhecimento das terras das populações indígenas era necessária através da presença de um aparelho que os representasse politicamente.

A crise do SPI ocorreu em meados dos anos 60 , já que havia acusações de genocídio de indígenas, corrupção e ineficiência. No final de 1967, foram extintos o SPI e o Parque Nacional do Xingu, e os acervos transferidos para a Fundação Nacional do Índio (FUNAI), criado para continuar o exercício da tutela do Estado sobre os indígenas.

Assim, a FUNAI e seus princípios de ação encontraram-se baseados no mesmo paradoxo fundador do SPI (Pacheco de oliveira \& Rocha freire, 2006), respeito ao índio, à aculturação espontânea do índio e à educação dele para a sua progressiva integração à sociedade nacional. 
O SPI extingue-se melancolicamente em 1966 em meio a acusações de corrupção e é substituído em 1967 pela Fundação Nacional do Índio (Funai): a política indigenista continua atrelada ao Estado e a suas prioridades. Os anos 1970 são os do "milagre", dos investimentos em infraestrutura e em prospecção mineral - é a época da Transamazônica, da barragem de Tucuruí e da de Balbina, do Projeto Carajás. (Cunha, 2012, p. 21)

Com a substituição do SPI pela FUNAI, que tinha como objetivo a proteção das comunidades indígenas, provendo-os de toda ação de estado necessária e com a proteção de suas terras e representando-os juridicamente, em pouco tempo a mesma estaria submersa sob ditadura militar, na expansão sobre a Amazônia e nos planos desenvolvimentistas de integração nacional, cujos impactos sobre os povos indígenas seriam internacionalmente denunciados ao longo dos anos 1970 e 1980.

\footnotetext{
No meio dessa conjuntura, um pouco para dar satisfação aos credores internacionais do "desenvolvimento brasileiro", o regime militar aprovaria o Estatuto do Índio, lei 6.001/1973, de teor assimilacionista e tutelar, mas que, ainda assim, lançando as bases que permitiram a luta por um novo direito, sobretudo às terras que ocupavam os povos indígenas, em meio à desenfreada corrida às terras amazônicas. (Lima, 2005, p. 244)
}

As pressões internacionais na época estavam permeadas pelas ideias de anistia e direitos humanos. A ação de movimentos internacionais de defesa dos direitos humanos e sobre o meio ambiente desafiava o princípio desenvolvimentista.

Os delineamentos jurídicos marcados pelo poder tutelar e por meio das políticas indigenistas lograram instaurar um modelo de integração para os povos indígenas. No entanto, as divergências sociais e políticas não faltaram e, portanto, o estabelecimento e surgimento de organizações indígenas com ajuda da agência de algumas organizações não indígenas ajudaram a delinear um novo horizonte para a luta $e$ reivindicação indígena a partir de suas políticas sem visar a integração.

Uma vez tendo definições operatórias sobre o pensamento ou as ideias que permearam o Estado nacional, na primeira metade do século XX em relação aos povos indígenas, o que caberia revisar é como, através desses enquadramentos políticos e sociais, os povos indígenas têm reclamado e reivindicado sua posição como comunidades políticas dentro do atual Estado nacional e como tem se apropriado dos diferentes conceitos ou categorias tais como cidadania e direitos, os quais são definidoras para o estabelecimento de políticas indígenas dentro dos aparatos estatais indigenistas. Sob esse eixo, o que interessa é revisar como, a partir dos movimentos indígenas surgidos na década de 1970, esses povos acunharam e apropriaram-se de uma série de categorias culturais e sociais que proclamaram novos modos de exercer direitos e cidadania, assim como a construção de organizações e movimentos indígenas.

Nesse sentido, nas últimas décadas do século XX, ocorreu uma nova configuração política, histórica e social. No Brasil, a partir da instauração da Constituição de 1988, logo após a ditadura militar, os indígenas passaram a ser comunidades políticas e culturais respeitadas e reconhecidas como tais.

As associações civis de defesa aos índios e outras ONGs surgiram nos anos de 1970 e 1980. Na década de 1990, muitas dessas organizações foram executoras de políticas fundamentais no âmbito regional e local. A 
abertura de espaços e a criação de novas ideias marcaram, assim, uma nova discussão que abrangeria a questão da cidadania indígena e dos direitos indígenas. Sob esse eixo, nos anos 70 , os indígenas começaram a ser vistos por outra perspectiva, discutindo e reivindicando seus direitos. Mário Juruna, índio Xavante, que questionava políticos e indigenistas, impulsionou o movimento pela cidadania indígena. Nas últimas décadas do século $X X$ repercutiram com vigor as iniciativas e as demandas indígenas em relação ao território.

O território foi a principal bandeira, e foi o que motivou a luta pela Constituição Federal, em 1988, quando as lideranças participaram ativamente para garantir os direitos. As mobilizações que apresentaram e abrigaram novos atores e novas formas de ação lograram colocar um contraponto no poder tutelar e abrir novos temas e prioridades para a agenda nacional em matéria de cidadania indígena.

A partir das mobilizações, o chamado movimento indígena tinha como fundamento quebrar com a crença fundamental de ter que aguardar ou solicitar a intervenção protetora para que o Estado reconhecesse seus direitos. Os indígenas precisavam ter uma mobilização própria, estabelecendo vínculos e dando a conhecer a opinião pública suas lutas. "As décadas de 70 e 80 foram os momentos de maior visibilidade dessa modalidade de ação política, que se constituía à margem da política indigenista oficial, opondo Estado e sociedade civil, delineando progressivamente novas modalidades de cidadania indígena." (Pacheco de oliveira \& Rocha freire, 2006, p 187).

Após a consolidação do movimento indígena e com os novos direitos reconhecidos para os povos indígenas na Constituição brasileira de 1988, abriu-se a possibilidade de existir relações interétnicas menos assimétricas do que no passado (Baines, 2008).

\begin{abstract}
A década de 1970 representou o início de diversas alianças entre grupos indígenas para conquistarem direitos comuns. O Primeiro movimento que conseguiu reunir índios de diferentes etnias foi ConseIho Indigenista Missionário (CIMI), reunindo em sua primeira assembleia, em 1974, 17 (dezessete) índios e em seu segundo encontro 60 (sessenta) índios. A mobilização da Igreja Católica a favor da causa indígena é consequência da II Conferência Geral do Episcopado Latino em Medellín (1968), em que a Igreja Católica assume que atuou, muitas vezes, junto ao colonizador contra aos povos indígenas e cria o Conselho Indigenista Missionário (CIMI), em 1972. (Nascente, 2010, pp. 9-10)
\end{abstract}

A abertura de s debates e ações por parte dos indígenas tiveram ressonância na sociedade e plantou-se a necessidade de criar uma sociedade menos assimétrica e que dera conta das demandas indígenas.

Adefesa de direitos questionava a tutela oficial, levantava a importância das assembleias e das organizações e permitiram o conhecimento da diversidade de povos e culturas indígenas no Brasil. Assim, instrumentalizavam a categoria "índio" para unificar reivindicações e lutar por direitos. A luta era para juntar uma causa comum (Pacheco de oliveira \& Rocha freire, 2006). Nesse sentido, as relações sociais entre os povos indígenas e a sociedade nacional e com o Estado mudaram e colocaram questionamentos na matéria do direito e na política brasileira. As críticas eram contra um modelo e sistema que baseava-se nas imensas desigualdades do poder através do qual a sociedade nacional expande-se sobre os territórios indígenas e com as perspectivas assimilacionistas. 
O crescimento do movimento indígena a partir da década de 1970, a crescente pressão política por parte das lideranças indígenas a nível nacional e internacional para assegurar seus direitos, e uma intensa mobilização dos índios no processo constituinte junto com organizações de apoio, culminaram em várias modificações na Constituição brasileira de 1988. Estas modificações trouxeram potencial para mudar as relações entre os povos indígenas e o Estado. Duas inovações muito importantes, que representam uma inovação em relação às Constituições anteriores, são o reconhecimento dos direitos dos índios sobre suas terras como direitos "originários" pelo fato dos índios terem sido os primeiros ocupantes do Brasil, e o abandono da perspectiva assimilacionista que entendia os índios como uma categoria transitória destinada a desaparecer. (Baines, 2008, p. 8)

Um dado importante é que a Constituição de 1988 marca o fim das tentativas assimilacionistas e integracionistas do Estado, ao estabelecer o princípio de que os povos indígenas constituemse em sujeitos coletivos de direitos coletivos.

Outra inovação importante é que se reconhece, no Artigo 232, que "Os índios, suas comunidades e organizações são partes legítimas para ingressar em juízo em defesa de seus direitos e interesses, intervindo o Ministério Público em todos os atos do processo", dispensando a FUNAI de ser sua representação. Os povos indígenas passaram a ser considerados como sujeito de ação jurídica, seguindo a tendência internacional de constitucionalizar direitos indígenas. (Baines, 2008, pp. 8-9)

É somente no avançado século XX que se tem mais clara a importância da diversidade, "A Constituição de 1988 reconhece aos índios o direito de ser índio, de manter-se como índio, com sua organização social, costumes, línguas, crenças e tradições. Além disso, reconhece o direito originário sobre as terras que tradicionalmente ocupam." (Souza filho, 2010, p. 107).
Depois da tutela do Estado, as resistências e as organizações políticas dos povos indígenas marcaram a história do Brasil. O crescimento de organizações indígenas tem sido um papel fundamental na pressão para a concretização e consolidação de direitos indígenas (Baines, 2008).

No fim da década de 1970 multiplicam-se as organizações não governamentais de apoio aos índios, e no início da década de 1980, pela primeira vez, se organiza um movimento indígena de âmbito nacional. Essa mobilização explica as grandes novidades obtidas na Constituição de 1988, que abandona as metas e o jargão assimilacionistas e reconhece os direitos originários dos índios, seus direitos históricos, à posse da terra de que foram os primeiros senhores. (Cunha, 2012, p. 22)

Cabe ressaltar que o mais importante está no texto constitucional, significa o reconhecimento dos direitos indígenas e o respeito a esses povos e como, a partir disso, a tutela foi quebrada.

Como a constituição estabeleceu o Ministério Público Federal como instância de defesa dos povos indígenas contra o Estado, a efetiva atribuição de capacidade processual civil pelo texto constitucional de 1988 às comunidades indígenas e suas "organizações" (no que para muitos foi o "fim" da tutela) significou a proliferação, desde então, sobretudo na Amazônia, de organizações locais - associações, federações, etc. -, e supralocais, congregando um grupo indígena específico, ou articulando diversos grupos de uma mesma região, etc., com funções de representação política e jurídica. Muitas dessas associações têm hoje vínculos e projeção internacionais, integrando um panorama heterogêneo e mal conhecido. A Coordenação das Organizações Indígenas da Amazônia Brasileira (COIAB), o Conselho Indígena de Roraima (CIR), a Federação das Organizações Indígenas do Rio Negro (FOIRN), Articulação dos Povos e Organizações Indígenas do Nordeste, Minas Gerais e Espírito Santo (APOINME), são quatro organizações de âmbito regional muito distinto com funções e ação muito diferentes dos modelos verticalizados e "sindicalistas" de 
associativismo que o senso comum tem em mente, e que têm percorrido o árduo caminho de construir novas possibilidades de interlocução. A elas junta-se a participação indígena em legislativos (municipais sobretudo) ao longo do país. (Lima, 2005, p. 246)

Nesse sentido, a questão indígena com suas organizações de articulação regionais e nacionais, passa também a se discutir no âmbito internacional. Com as mobilizações a nível supranacional, os movimentos sociais indígenas tiveram maior força para lutar por direitos à propriedade de suas terras, assim como outros direitos básicos como saúde e educação (Nascente, 2010). No entanto, se reconhece que o modelo tutelar constituinte do SPI e da FUNAI encontrou seu fim legalmente com a Constituição de 1988 não se pode pensar que se criaram alternativas que o ultrapassassem.

\begin{abstract}
Mas reconhecer o "fim jurídico" da tutela da União não basta: não acabaram de fato as formas tutelares de poder, moralidades e de interação; a Funai continua a existir segundo o modelo tutelar sem um novo projeto das funções de Estado para o relacionamento entre povos indígenas, poderes públicos e segmentos dominantes da sociedade brasileira, delineado e pactuado por todos os envolvidos, sobretudo pelos povos indígenas. A crença em certas palavras de ordem, muitas delas coincidentes com a agenda da cooperação técnica internacional, segundo as regras neoliberais, e uma dada destilação dos ideais de uma "democracia participativa" acabaram por gerar um certo glossário de palavras de ordem significantes mais ou menos vazias. (Lima, 2005, p. 246)
\end{abstract}

Assim, caso existam um vazio ou lacunas e fronteiras entre o discurso e a prática, caberia questionar e analisar o funcionamento atual e as relações que se constroem entre os indígenas e a sociedade nacional.

\section{As lutas indígenas à luz dos Movimentos Sociais}

Para poder entender as ações, as lutas e as reivindicações dos povos indígenas e relacioná -las com a temática sobre cidadania, é interessante revisar a ideia do movimento social como uma conduta coletiva organizada que luta contra seu adversário pela direção social da historicidade em uma coletividade concreta. Vemos assim uma convergência das ideias dos novos movimentos sociais, com os movimentos sociais da América Latina (Gohn, 2002; 2003).

Nesse sentido, as orientações culturais estão relacionadas com o conflito social: "yo sostengo que el campo cultural, la historicidad de una sociedad es el lugar de los conflictos más importantes. La sociedad es producción conflictiva de ella misma." (Touraine, 2006, p. 255). Para Touraine, na América Latina a análise social encontra-se dominada pelo estudo do sistema capitalista mundial, da troca desigual. Nesse sentido, sinaliza que os atores sociais populares ao interior das suas sociedades aparecem como desintegrados ou subsumidos pela dominação que vem do exterior. Vale ressaltar que a categoria de movimentos sociais ajuda a entender as condutas socialmente conflitivas, mas também culturalmente orientadas.

É interessante como se sinaliza a ideia de que o movimento social não só é uma afirmação, uma intenção, é uma dupla relação, tem um adversário e um enjeu ${ }^{1}$.

El movimiento social se presenta como la combinación de un principio de identidad, un principio de oposición y un principio de totalidad. Para luchar, ¿no es necesario saber en nombre de quién, contra quién o sobre qué terreno se lucha? Reducir a estas simples ideas el esquema aplica a todas las conductas sociales puesto que todas colocan al actor en una relación y no hay relación sin campo social. (Touraine, 2006, p. 259) 
Um movimento social se situa dentro de um sistema social onde ele questiona as forças dominantes e seus apoios políticos ou culturais. Touraine (2006) afirma que os movimentos sociais estão associados às práticas de luta, às formas de mudança social, mas a sua definição se estabelece sobre a análise do funcionamento das sociedades.

\section{Un movimiento social no interviene solo y no está jamás separado completamente de reivindicaciones y de presio- nes, de crisis y de rupturas que dan nacimiento a unos tipos diferentes de luchas. Yo llamo luchas a todas las formas de acción conflictivas organizadas y conducidas por un actor colectivo contra un adversario por el control de un campo social. Un movimiento social es el tipo parti- cular de lucha más importante. (Touraine, 2006, p. 262)}

Nesse sentido, se sinaliza a ideia de que as lutas e as reivindicações dos indígenas ou grupos étnicos tentam abrir ou expandir o conceito de cidadania e de afirmação de direitos dentro dos Estados-nacionais.

El actor (I) no puede acceder al campo de decisión $(\mathrm{T})$; este es ocupado por el adversário $(\mathrm{O})$, quien vigila las puertas. El actor está en lucha directa contra su adversario pero busca forzar la entrada de una institución pues él no pone en tela de juicio la legitimidad.

(Touraine, 2006, p. 266)

Um movimento indígena pode estar relacionado com um movimento de corte cultural, o movimento cultural leva, ele mesmo, uma oposição social. Nesse sentido, está ligado às relações de dominação que outorgam duas expressões opostas à mesma ação geral de transformação cultural (Touraine, 2006).

Estabelecendo que o movimento indígena faz parte dos novos movimentos sociais que surgiram na metade do século $\mathrm{XX}$, devido ao passo e a mudança nos Estado-nacionais onde a partir da abertura dos movimentos sociais para as minorias, as mulheres, grupos étnicos, estabelece-se outro modo de exercer cidadania e direitos.

\begin{abstract}
La década de los noventa se reveló como un tiempo histórico rico en posibilidades y complejo en su interpretación y en cuyo interior se dio la eclosión de nuevos movimientos sociales y, entre estos, los movimientos indígenas. En toda América Latina, insurge con mucha fuerza un entramado social y organizativo basado en la vida comunitaria de los pueblos indígenas, que servirá de sustento para la movilización social y política de muchos movimientos sociales en el continente. (Dávalos, 2005, p. 17)
\end{abstract}

Na América Latina, a eclosão do movimento indígena situa-se em um contexto em que as políticas neoliberais geram graves fraturas sociais e vulneram a distribuição equitativa na sociedade. A presença dos movimentos sociais indígenas na América Latina outorga uma nova dimensão à participação e luta social e ao mesmo tempo incorpora temáticas novas na agenda política: "producto de ellos serán las movilizaciones en contra de la reforma estructural, pero también por la autonomía y el respeto a sus derechos, que protagonizarán los movimientos indígenas en todo el continente." (Dávalos, 2005, p. 18).

A presença política dos movimentos indígenas na América Latina tem-se estabelecido dentro de uma crise política e de imposição de políticas neoliberais. Assim, não só tem marcado uma posição de defesa de sua cultura e sua identidade senão também tem colocado propostas de reformular o regime político, de transformar o Estado, de mudar os sistemas de representação, de outorgar novos critérios à democracia, expandindo a participação comunitária (Dávalos, 2005). Nesse sentido, a partir dessas novas experiências políticas e de conformação 
de movimentos indígenas, o debate político tem-se enriquecido e tem incorporado novas temáticas que colocam o reconhecimento, a diferença e, sobretudo, a necessidade de construir uma participação social.

Os povos indígenas através das suas lutas pretendem rearticular seu sistema de saberes dentro de um marco institucional próprio: "y dentro de un campo de luchas en el cual cobran validez tanto el reconocimiento como pueblos con identidades diferentes, como el establecimiento de universidades propias, o las demandas de educación intercultural." (Dávalos, 2005, p. 24).

Vale ressaltar que a partir da constituição dos Estados nacionais, os indígenas seriam excluídos e dentro dos marcos constitucionais que se estabeleceram dentro das repúblicas latino -americanas, a figura do cidadão não contemplava a diferença e excluía de maneira explícita aos indígenas de todo o sistema de representação e de todo o aparato institucional do Estado.

Las primeras constituciones de las repúblicas que se conformaron en América, a lo largo del primer y segundo tercio del siglo XIX, hablan del ciudadano pero en la acepción burguesa de los derechos políticos. Los indios simplemente no existen. El proyecto de la razón los había invisibilizado. (Dávalos, 2005, p. 25)

Como já foi mencionado, é importante sinalizar que durante a metade do século $X X$ a emergência dos movimentos indígenas vai se orientar ao caráter autônomo e de luta pela reformulação dos Estados-nacionais e do reconhecimento dos direitos indígenas, assim como da participação cidadã na tomada de decisões. Nesse sentido, é importante ressaltar que uns dos acontecimentos significativos na década de 70 do século $\mathrm{XX}$, no continente latino-americano, produziram-se levantamentos indígenas como no Equador e em janeiro de 1994 o movimento indígena zapatista, EZLN, no estado de Chiapas, México.

A formulação de que o Estado-nação tem fracassado no seu intento de constituir sociedades homogêneas indica um debate no qual os movimentos indígenas têm um espaço prioritário. Nesse sentido, visa-se transformar um Estado excludente em um Estado pluralista, tolerante, participativo, e sob esse delineamento os movimentos indígenas encontram sua causa de luta.

Nesse sentido, pensar que os grupos étnicos são formas de organização social que se relacionam com a identidade dos indivíduos do grupo, e que a partir dessas delimitações ou diferenças culturais estabelecem um ponto nodal que regula os encontros interétnicos, o que poderíamos relacionar seria o caráter político que muitas vezes os grupos étnicos denotam dentro das relações ou encontros sociais interétnicos, os quais, geralmente, vão ocasionar divergências (Barth, 1976). Assim, a linha de análise entre o movimento social indígena e os grupos étnicos encontra um ponto de alcance, já que o sentido organizacional e político dá o processo de formação tanto dos grupos étnicos como dos movimentos indígenas e é isso o que interessa para pensar o debate sobre cidadania e direitos.

Pensar nas lutas dos grupos étnicos é pensar em uma amplitude de demandas e reivindicações que abrangem reconhecimentos, igualdades ou autonomias dentro de um Estado territorial existente e nesse sentido não é um fenômeno recente.

La lucha de los grupos étnicos por obtener reconocimiento, igualdad o autonomía dentro del marco de un Estado territorial existente, o por ser independientes 
de dicho Estado, no es un fenómeno reciente. Estos esfuerzos, que en ocasiones vienen aparejados con conflictos violentos, han sido inherentes al proceso de información de los estados y de construcción nacional, el cual se generó en el mundo occidental en los siglos XVIII y XIX. (Stavenhagen, 2000, p. 7)

A luta dos grupos étnicos para obter reconhecimento dá-se dentro de um marco onde os intentos das elites dominantes de impor, preservar ou expandir sua hegemonia sobre outras etnias ou sobre o território que reclamam como próprio, é fundamental (Stavenhagen, 2000). Assim, a confrontação e as lutas políticas e conflitos civis são uma temática polêmica que abrange diversos grupos em diferentes partes do mundo. Vale ressaltar que a partir da perspectiva do Estado-nação moderno, a existência de grupos com diferenças étnicas representa uma ameaça potencial quando o poder do Estado reside em um grupo dominante ou quando a sociedade nacional constitui um sistema de estratificação étnica.

A problemática que se dá dentro dos Estados nacionais surge a partir da diversidade dos grupos étnicos que podem abrigar diferentes aspectos culturais, raciais, linguísticos e que não se identificam com o modelo predominante ou que não são aceitos por completo como membros desse Estado ou da nação que afirma ser ou representar, ou que são excluídos dela (Stavenhagen, 2000). Nesse sentido, a diversidade constitui um desafio para a governabilidade e para o conceito do Estado-nação. Um dos problemas é a falta de reconhecimento legal do pluralismo étnico. Portanto, é interessante ressaltar que os grupos étnicos podem receber o nome de comunidades, nações, nacionalidades, povos, minorias, tribos ou etnias que têm ou podem ter uma transcendência jurídica e política.
O termo "grupo étnico" tem um sentido neutral desde a perspectiva jurídica e política, ao passo que o termo "povo" tem um uso amplo na literatura jurídica e política e denota implicações particulares no direito internacional: "el 'termino "minorías" también tiene un significado específico en el derecho internacional, aunque su uso es más amplio por sus connotaciones demográficas." (Stavenhagen, 2000, p. 12). Dessa forma, se pensarmos nas lutas dos povos indígenas em matéria de direito e cidadania o termo "povo" seria o ponto nodal e relacional para orientar suas lutas, tanto no âmbito nacional como internacional. No entanto, as implicações significativas tanto do termo "grupos étnicos" como do "povo" são meramente políticas, identitárias e jurídicas e sob essa significação poderíamos atribuir a relação da temática étnica com os movimentos indígenas a partir de sua origem política e de identidade.

Para esclarecer as lutas dos povos indígenas, no geral, considera-se um caso especial cuja situação pode ser similar, mas não idêntica a das minorias étnicas ou nacionais, já que isto deve-se ao processo histórico em que os povos indígenas foram vítimas da conquista, colonização e o estabelecimento em suas terras originárias e tradicionais, e tem casos em que a população indígena é, na realidade, uma maioria demográfica (Stavenhagen, 2000).

A terminologia étnica na América Latina considera que as comunidades indígenas (ameríndios) encontram-se na escala baixa do desenvolvimento socioeconômico dentro dos Estados-nação unitários. O conceito de índio ou de grupos indígenas denota básicamente uma categoria cultural e socioeconômica: "los indígenas mismos prefieren ser reconocidos como "pueblos" más que "poblaciones", "comunida- 
des" o "minorías", ya que como pueblos consideran que pueden reclamar para sí ciertos derechos de acuerdo con los principios internacionales de derechos humanos." (Stavenhagen, 2000, p. 28).

Os movimentos indígenas nesse sentido, com seu caráter político e de luta, se relacionam com o caráter étnico já que tem a ver com a reivindicação cultural e de identidade e, portanto, a causa encontra a relação em um ponto comum, que seria o do reconhecimento jurídico do Estado e o reconhecimento cultural e identitário. A reformulação do Estado e a amplitude do conceito de cidadania encontra seu alvo nas demandas pelo direito à saúde, educação, território, moradia, que dentro do direito chamariam a outorgar os direitos coletivos. Nesse sentido, coloca-se o debate de pertencer a suas comunidades e ao mesmo tempo ao Estado-nação. Do mesmo modo, a problemática das populações não se reduz só às carências de ordem material nem do desafio do desenvolvimento econômico e social.

Nesse sentido, as violações aos direitos humanos dos grupos indígenas não só têm a ver com os processos de exploração e de despojo, tem a ver também com a negação sistemática da possibilidade de poder conservar suas próprias culturas incluindo línguas, costumes, modos de convivência e formas de organização social (Stavenhagen, 1988).

Vale ressaltar que a maioria dos indígenas na América Latina tem sofrido uma dupla exploração: por uma parte a exploração de classe por sua condição de camponeses pobres e marginais inseridos em sistemas de exploração da mão de obra. Por outra, por sua condição étnica, discriminados pelo racismo inerente e os sentimentos de superioridade cultural da sociedade nacional dominada pelos valores culturais ocidentais (Stavenhagen, 1988). Sob esses fatores, a exploração de classe e a discriminação étnica, apresentam-se violações de direitos humanos dos povos indígenas: genocídios, despojo de terras, não aplicação de garantias individuais nem coletivas constitucionais, discriminação na matéria de leis e de procedimentos judiciais, obstáculos para a participação.

Na temática sobre cidadania e direitos indígenas coloca-se o foco do debate nos movimentos indígenas. Através de suas lutas étnicas tentam reformular o Estado-nação e o sistema jurídico, abrindo uma nova temática no que se refere à questão de participação cidadã e de reconhecimento dos direitos coletivos. Nesse sentido, o sistema jurídico como conjunto de normas reguladoras da vida social pelo geral tem homogeneizado e imposto o critério monoétnico de escasso respeito ao pluralismo jurídico e à diversidade cultural.

A temática sobre 0 direito consuetudinário estabelece-se como prioritária dentro do aparato legal do Estado. O desconhecimento da legalidade indígena e do direito consuetudinário por parte da sociedade nacional, e por parte do Estado-nação, tem conduzido na maioria dos casos a violação dos direitos humanos.

Uma das grandes temáticas que se relacionam com as lutas dos movimentos indígenas tem a ver com a identidade que se gera através do seu vínculo com a terra. A terra é considerada não somente com um meio de reprodução ou recurso econômico, senão como um elemento ideológico, religioso, político e cultural, como se verá mais adiante. Nesse sentido, através da imposição, do despojo e de novas formas indivi- 
dualizadas da propriedade da terra, os governos têm sabido como agir intencionalmente e entram em conflito com as formas estabelecidas de convivência e organização social. Umas das questões a serem resolvidas dá-se no sentido de como reconhecer e dar legitimidade a formas diferentes da estrutura jurídica nacional.

Tendo como temática a questão dos movimentos sociais indígenas e as reivindicações étnicas, se tratando de povos indígenas, o grande foco são as análises e discussões que se enquadram nos debates políticos, sociais e culturais, abarcam e abrangem as temáticas dos direitos e do exercício da cidadania. O pensamento que se expressa através dos grupos indígenas, em suas manifestações tem como pontos comuns:

La recuperación y valoración de las lenguas propias como vehículo y expresión de la conciencia colectiva de cada nacionalidad india; la recuperación y afirmación de la racionalidad de cada grupo indígena en sus relaciones con la naturaleza; la reactualización histórica de la idea y del proyecto de territorialidad étnica como sustento material y simbólico de cada grupo; la formulación de una política y de una práctica autónoma en todo lo que atañe a la vida en el interior del grupo. (Stavenhagen, 1988, p. 125)

Por outro lado, vale ressaltar que o debate sobre os direitos coletivos demandados pelos movimentos indígenas é um tema de suma importância dentro da relação dos povos indígenas com o Estado-nação e com o sistema jurídico. Geralmente, os direitos coletivos têm a ver com os direitos territoriais, políticos, educativos e linguísticos, a autodeterminação, sobre recursos naturais e saúde, mas uma das discussões centrais se estabelece na questão territorial.
Discutir a questão da cidadania indígena e direitos indígenas supõe um campo amplo que dá conta de múltiplos processos sociais e políticos, que abrangem variadas vozes de diversos sujeitos, tanto indígenas como não indígenas. Os discursos variados e as interações que se encontram no relacionamento entre os diferentes sujeitos, supõem um exercício de contextualização e de análise. Nesse sentido, não existe uma homogeneidade discursiva nem situações iguais, o que existe de semelhante é a luta comum que, geralmente os povos indígenas abrangem desde os anos de 1970 no Brasil e, especificamente, no estado de Roraima. Entender que a luta pelos direitos e a cidadania é um campo diverso, já que atinge vários campos sociais, ajuda a diferenciar e analisar o conceito e adequá-lo ao contexto específico.

Pensar na possibilidade de entender e debater a cidadania a partir da perspectiva dos povos indígenas, desde as bases, ajuda a refletir outra maneira de apropriação do conceito e, sobretudo, entender que a unidade ou homogeneidade do conceito na prática difere no discurso, tanto juridicamente como socialmente. A necessidade de entender, debater e exercer outro tipo de cidadania surge devido ao contraste que se tem com aquela cidadania liberal dos Estados nacionais, aquela que é homogênea, unitária e monocultural. Assim, estabelece-se o interesse por analisar as novas dimensões do sentido da cidadania e do exercício de direitos, para pensar na possibilidade de estabelecer outra ordem social, cultural e política dentro da sociedade e do Estado que continua discriminando e dominando os povos indígenas e grupos minoritários da América Latina. 


\section{Os movimentos indígenas}

Como vimos, a segunda metade do século XX marca um novo cenário mundial que vai ajudar a repensar as práticas políticas com os povos indígenas e, sobretudo, vão surgir políticas indígenas e organizações indígenas que estabeleceram novos caminhos dentro da cidadania indígena e política indígena.

As primeiras reuniões regionais indígenas tiveram lugar nos anos de 1970 e foram auspiciadas pelo Conselho Missionário Indigenista (CIMI). As décadas de 1970, 80 e 90, por outro lado, foram caracterizadas pelo ressurgimento de ações indigenistas. Esse impulso se deu pela reação à grande invasão das T.I. Yanomami e da Raposa Serra do Sol, que se processava devido à corrida do ouro (Repetto, 2008). O surgimento de organizações indígenas sob esse contexto veio com a necessidade de recuperar os territórios invadidos por garimpeiros e fazendeiros. Assim, com a extinção do SPI, em 1967 e com a sucessão da Fundação Nacional do Índio (FUNAI), e diante desse quadro de invasões, a Funai foi instituída com o objetivo de exercer o monopólio tutelar provendo a ação necessária para os indígenas em relação à proteção das suas comunidades indígenas representando-as juridicamente (Lima, 2005).

Vale ressaltar que em 1985 os militares devolveram o governo federal aos civis durante - que foi chamado como a "nova república" (Ramos, 1998). Assim, a questão indígena foi um inconveniente para os políticos e os grupos de interesse. Nesse sentido, a primeira organização indígena nacional, União Nações Indígenas (UNI) foi criada em 1980. Nesse período, a FUNAl, assim como outras instituições do governo, era dirigida pelos militares.
Tentando enquadrar a análise dos conflitos locais dos povos indígenas de Roraima com os processos nacionais, pode-se pensar em relacionar e visualizar os desafios comuns marcados e manifestados que surgiram dentro dos acirrados contextos de assimilação, maltrato e tutela, tanto pelos povos indígenas como pela sociedade civil e alguns organismos independentes, "as associações civis de defesa aos índios e outras ONGs surgidas em torno de 1978/1980 tinham perfis e tomaram rumos muito distintos. Na década de 1990, muitas dessas organizações tornaram-se executoras de políticas fundamentais no âmbito regional e local." (Lima, 2005, p. 244).

Assim, tem surgido movimentos sociais indígenas que estabelecem demandas sobre a valorização da cultura, território, justiça, educação e direitos humanos. A partir das diferentes etapas políticas e sociais que fazem parte do exercício da cidadania dos povos indígenas, ajudam a entender essas relações que se estabelecem até hoje entre os indígenas e não indígenas, e os diferentes modos de agir nessas relações verticais, nessa realidade tão complexa que é dos povos indígenas em Roraima.

Um tema importante que continua surgindo dentro de algumas análises é o caso de compreender, ao longo da história, como o território indígena tem sido desterritorializado e reterritorializado, marcando conflitos entre os indígenas e não indígenas e entre os próprios setores indígenas. Geralmente os conflitos fundam-se nas demandas e lutas por parte dos povos indígenas para a modificação do Estado, que não tem respeitado, na prática, os direitos indígenas, no caso da demarcação e homologação do território. 
Roraima é o cenário de fortes conflitos territoriais que se cristalizam na definição de políticas indigenistas e indígenas, acarretam fortes atritos entre diferentes setores indígenas, mas também entre grupos não-indígenas detentores do poder local, bem como entre estes grupos de não-indígenas e os diferentes setores indígenas. (Repetto, 2008, p. 20).

contexto político e a movimentação dos povos indígenas de Roraima teve um impulso a partir da década de 1970 quando as lutas e as reivindicações pelos direitos territoriais tiveram um forte embate e desdobramentos na realidade do estado e do país. Nesse sentido, as temáticas que são analisadas em algumas pesquisas surgem do interesse de entender como se originou a mobilização da sociedade civil na defesa pelos direitos territoriais dos povos indígenas, com ênfase especial na década 1970. Especificamente, os conflitos fundiários em território Macuxi, no estado de Roraima, que vão desde a década de 70 até 1990 (Santilli, 2001) são considerados um momento forte entre o reordenamento jurídico e institucional no país, no qual o reconhecimento das terras indígenas pelo Estado é incluído como necessário.

Para exemplificar alguns casos sobre os conflitos territoriais no estado de Roraima, pode-se mencionar o caso da Raposa Serra do Sol.

\footnotetext{
Raposa Serra do Sol is the traditional área of a number of indigenous peoples- Makushi, Wapishana, Ingarikó, Taurepang, and Patamona- with a total population of about twelve thousand Indians living in ninety-four villages. A proposal to demarcate its nearly 1.7 million hectares was sent to the Ministry of Justice in 1993. (Ramos, 1998, p. 265)
}

A problemática concernente à Raposa Serra do Sol teve a ver com as relações conflitivas entre indígenas e não indígenas, sendo garim- peiros, fazendeiros, grupos de poder local. $O$ garimpo desencadeou fatores de desequilíbrio ambiental e social. Até o final da década de 80 do século $X X$, o garimpo encontravase amplamente espalhado de forma ilegal na área Yanomami. Depois do fechamento do garimpo naquela área, a atividade provocou um deslocamento dos garimpeiros para a terra indígena na Raposa Serra do Sol. A terra, por não se encontrar regularizada enquanto Terra Indígena, sofreu um grande impacto por parte dos garimpeiros.

Na década de 1990, depois de fortes pressões para expulsar os garimpeiros da área Yanomami, estes passaram em massa para a T.I. Raposa Serra do Sol, afetando diretamente aos Makuxi, Taurepang e Ingarikó. O auge da extração de ouro e diamantes nos garimpos localizados nas terras indígenas Yanomami e Raposa Serra do Sol, trouxe consigo um crescimento na demanda de gêneros de consumo, e o consequente aumento do comércio e de invasões de terras. (Repetto, 2008, p. 34)

A partir da chegada dos garimpeiros na Raposa Serra do Sol, a gravidade e a intensificação dos casos de violência adquiriram proporções alarmantes. Com isso, a inoperância das instâncias de governo responsáveis pela regularização das terras indígenas foi notável.

Por outro lado, vale lembrar que grande parte dos políticos locais da bancada de Roraima no legislativo, organizações corporativas, representantes da mineração e militares foram contrários à demarcação da Raposa Serra do Sol.

Apesar de todas as contestações jurídicas e conflitos promovidos por grupos contrários à homologação no ano de 2005, o Ministro da Justiça reconheceu a área contínua demarcada pela FUNAI. 
A FUNAI, nesse aspecto, tem sido uma aliada das comunidades indígenas. Assim, muitos dos ataques aos índios em Roraima, também o fazem para a FUNAI, já que é o agente que oficialmente ataca as pretensões dos invasores nas áreas indígenas. Por outro lado, é interessante destacar que a demarcação das terras indígenas muitas das vezes pode ser vista como contrárias ao desenvolvimento.

Demarcar terras indígenas sempre foi visto como um atraso ao desenvolvimento econômico. Usa-se, nesse caso, o critério quantitativo, isto é, a insistência na tese de ser "muita terra para pouco índio", o que é, no mínimo, estranho num país de latifúndio por excelência, onde também não são raras as fazendas maiores que alguns países europeus. Não custa nada lembrarmos que o Brasil possui uma estrutura fundiária extremamente concentrada, a maior que a história da humanidade já registrou. (Vieira, 2007, p. 4)

Dessa forma, o acúmulo de terras é importante para o contexto de expansão capitalista em detrimento das terras indígenas.

Para a maioria das organizações indígenas, a demarcação de terras é condição indispensável para que se possa falar em "desenvolvimento" - aí entendido como melhorias das condições de vida das pessoas. No entanto, algumas organizações indígenas discutem as demarcações aceitando a permanência dos chamados "invasores". Mas até mesmo entre os que aceitam a demarcação em "ilhas" há a consciência de que é imprescindível a criação de alternativas econômicas e sociais e que, além das demarcações dos territórios, necessitam de investimentos e, consequentemente, de entidades com as quais possam fazer parcerias para trabalhar em benefício das comunidades. (Repetto, 2008, p. 88)

Apesar dos conflitos entre indígenas e não indígenas também existem conflitos entre os próprios setores indígenas, como foi mencionado anteriormente. Isso deve-se ao fato de que algumas organizações preferem áreas contínuas (grandes) e outras preferem "ilhas" (pequenas).

Assim, comparando a situação das terras pequenas com as maiores, como São Marcos ou Raposa Serra do Sol, podemos ver um fator político, uma vez que as terras em ilhas foram promovidas como forma de evitar conflitos, inclusive por agentes do Estado. A defesa de terras maiores era vista como um problema, pois prolongava os atritos (Repetto, 2008).

Como se pode observar até agora, uma parte da história de Roraima, tem sido a história do conflito entre os que defendem e entre os que são contra a demarcação de terras indígenas. Para diversos grupos de interesse, a demarcação das terras indígenas inviabiliza o desenvolvimento econômico do Estado. Nesse contexto tem sido utilizados discursos sobre o desenvolvimento para manipular os discursos locais contra a demarcação das terras indígenas, ou seja, contra o reconhecimento destes direitos. Grupos de interesse colocaram a demarcação de terras indígenas como fosse um empecilho ao desenvolvimento do Estado de Roraima, contudo vemos que a corrupção e o desvio de recursos, que constantemente são denunciados em Roraima, são muito mais importantes para compreender os problemas estruturais que enfrenta o Estado.

Contudo as reivindicações por terra e os conflitos pelo reconhecimento territorial não tem sido as únicas lutas dos povos indígenas. Nas assembleias que surgiram desde os anos setenta, eram três as principais bandeiras de reivindicações: terra, saúde e educação. Estas demandas geraram importantes lutas em torno do exercício da cidadania. 
A luta por um atendimento diferenciado no campo da saúde gerou uma forte mobilização indígena no Brasil, uma vez que existe o reconhecimento de que nesse campo os povos indígenas enfrentam uma grande vulnerabilidade em relação ao resto da sociedade. A precariedade imunológica tem sido abertamente utilizada como uma guerra biológica, com conhecidos casos de infecção deliberada de sarampo, no passado, ou de gripe e de COVID-19 na atualidade, em especial em contextos de invasão territorial, como no caso que atualmente afeta as invasões de garimpo e mineração ilegal em terras do povos Yanomami.

Essa luta permitiu que o Estado reconhecesse a necessidade de um atendimento especial no campo da saúde, o que gerou toda uma política nacional de Distritos Sanitários Especiais Indígenas, o que tem permitido melhorar o atendimento inicial a estas populações.

Assim também a educação tem sido um capo de lutas, com reivindicações por uma educação específica e diferenciada, potencializada desde o movimento de professores indígenas da Amazônia, desde final dos anos oitenta, que levaram a criação de organizações como a Organização dos Professores Indígenas de Roraima (OPIR) e a Coordenação de Professores Indígenas do Amazonas, Roraima e Acre (COPIAR), que depois passou ase chamar Conselho dos Professores Indígenas da Amazônia (COPIAM) (Silva, 2000).

Esse movimento de professores indígenas questiona o modelo assimilacionista imposto pela escola nas comunidades indígenas e reivindica uma educação que possa utilizar e valorizar as línguas e conhecimentos indígenas. Esse debate levou a criação de diversos cursos de formação de professores indígenas em nível de magistério e hoje no Brasil existem uns 25 cursos de Licenciatura Intercultural destinados a formação de professores indígenas.

Vemos assim como a luta por terra, por saúde e por educação tem levantado demandas, propostas e ações concretas, nas quais a agencia do movimento indígena tem sido de grande relevância. Vemos também como estas reivindicações nos mostram um caminho para construir e ampliar os sentidos da cidadania. A qual muitas vezes é apresentada como relacionada apenas ao exercício do voto em pleitos eleitorais. Esta luta do movimento indígena nos mostra como o exercício da cidadania vem se ampliando e envolvendo diversos aspectos da vida das comunidades e da sociedade em sentido mais amplo.

Ainda, em 2018, em Roraima foi eleita a primeira mulher indígena deputada federal, a Sra. Joenia Wapichana, o que sem lugar a dúvidas é resultado dessas lutas, que também estão mirando e disputando os espações de representação nacional, estadual e municipal.

\section{A modo de conclusão}

Entende-se que a apropriação do território é dada em termos de instrumentalização (no sentido da utilização dos recursos naturais e da apropriação deles para desenvolver técnicas de sobrevivência). O território também se encontra envolvido em uma utilização política e administrativa, seja por parte do Estado ou por outros grupos sociais. Portanto, a partir desta relação dialética, o território apresenta uma importância enquanto objetivo político, social e cultural que, em muitos casos, gera conflitos em torno dele. Do mesmo modo, o 
território, tem adquirido um papel importante dentro da vida dos povos indígenas, pois a partir dele se tem estabelecido demandas e lutas que abrangem o exercício cidadão. Por outro lado, existem ainda outros temas que, de igual maneira, devem ser atendidos e debatidos para poder exercer uma cidadania plena, como desde os anos de 1970 o movimento reivindicava Terra, Saúde e Educação.

É necessário entender que através dos relacionamentos diferenciados entre os indígenas e não indígenas surgiram novos debates e diálogos de incidência para ter acesso e reconhecimento a sua cidadania. Tem-se, por um lado, que debater como geralmente os direitos surgiram através das demandas que são inseridas dentro de uma lógica cidadã diferente, que se separa do sentido individualista de um modelo de Estado-nação, e que se relaciona, na maioria dos casos, com uma cidadania que possa dialogar e ser reconhecida coletivamente e, sobretudo, praticada e vivida plenamente.

Vimos como desde a formação do indigenismo e do poder tutelar se delineou uma ação estatal para com os povos indígenas que marcou o século XX por uma política de assimi- lação e integração forçada dos povos indígenas ao Estado Nacional Brasileiro. Essa política, no discurso veio mudar significativamente a partir da constituição de 1988.

Este tema, contudo, ainda precisa ser discutido e aprofundado, pois nos últimos anos vemos como o exercício dos direitos cidadãos dos povos indígenas continuam a enfrentar desafios e vulnerabilidades, uma vez que a tutela e a imposição voltam a aparecer e a colocar em perigo as conquistas e os direitos cidadãos básicos.

As lutas e reivindicações do movimento indígena nos mostram como pode ser ampliado o sentido do exercício de direitos e da cidadania, tanto ao envolver de forma significativa aspectos importantes da vida das pessoas nesse momento histórico particular, como no sentido de colocar em xeque a perspectiva liberal individualista da cidadania e do exercício dos direitos, pois terra, saúde e educação se referem a um campo de direitos coletivos, o qual cada vez ganha mais espaços e reconhecimentos no contexto internacional, sobre os quais as sociedades nacionais ainda têm muito a aprender com os povos indígenas.

\section{Notas}

\footnotetext{
1 Termo central da teoria de Touraine, o enjeu de um jogo ou uma luta é "o que está em jogo", aquilo pelo que se luta; "aposta", "objetivo".
} 


\section{Referências bibliográficas}

Baines, S. (2008). Identidades indígenas e ativismo político no Brasil: depois da Constituição de 1988. Série Antropologia, 418, 6-18.

Barth, F. (1976). Introducción. En Barth, F. (Ed.), Los grupos étnicos y sus fronteras. La organización social de las diferencias culturales (pp. 9-49). México D.F.: Fonde Económico de Cultura.

Celarié, A. (2016). Reflexões Sobre os Sentidos da Cidadania: desde a diversidade da América Latina aos conflitos indígenas em Roraima, Brasil. (Dissertação de mestrado). Universidade Federal de Roraima (UFRR), Boa Vista, RR.

Carneiro da Cunha, M. (2012). Índios no Brasil: história, direitos e cidadania. São Paulo: Claro Enigma.

Davalos, P. (2005). Movimientos Indígenas en América Latina: el derecho a la palabra. En Davalos, P. (Ed.), Pueblos indígenas, estado y democracia (pp. 17-33). Buenos Aires: Consejo Latinoamericano de Ciencias Sociales (CLACSO).

Gellner, E. (1988). Naciones y nacionalismo. Madrid: Alianza Editorial.

Gonh, M. (2003). Movimentos Sociais na atualidade: manifestações e categorias analíticas. En Gonh, M. G. (Ed.), Movimentos sociais no início do século XXI: antigos e novos atores sociais. Petrópolis: Vozes. (2002). Teorias dos Movimentos Sociais: paradigmas clássicos e contemporâneos. São Paulo: Edições Loyola.

Lima, A. (2005). Os povos indígenas na invenção do Brasil: na luta pela construção do respeito à pluralidade. En Lessa, C. (Ed.), Enciclopédia da brasilidade: auto-estima em verde amarelo (pp. 234-247). Rio de Janeiro: Casa da Palavra Produção Editorial. (1995). Um grande cerco de paz: poder tutelar, indianidade e formação do Estado no Brasil. Petrópolis: Vozes.

Nascente, L. (2010). Política e construção da identidade nacional: os índios na história do brasil. Revista Litteris - Ciências Humanas - Antropologia, (6), 1-15.

Pacheco de oliveira, J. \& Rocha freire, C, A. (2006). A Presença Indígena na Formação do Brasil. Brasília: Ministério da Educação/ Secretaria de Educação Continuada/Alfabetização e Diversidade/ LACED/Museu Nacional.

Ramos, A. (1998). Indigenism: Ethnic politics in brazil. United States of America: The University of Wisconsin Press.

Repetto, M. (2008). Movimentos indígenas e conflitos territoriais no estado de Roraima. Boa Vista: Editora da Universidade Federal de Roraima (UFRR).

Santilli, P. (2001). Pemongon Patá: Território Macuxi, rotas de conflito. São Paulo: Editora Universidade Estadual Paulista (UNESP).

Silva, R. (2000). Escolas em movimento: trajetória de uma política indígena de educação. Cadernos de Pesquisa. no.111. São Paulo. (http://dx.doi.org/10.1590/S0100-15742000000300002)

Souza filho, C. (2010). O Renascer dos Povos Indígenas para o Direito. Curitiba: Juruá.

Stavenhagen, R. (2000). Conflictos étnicos y estado nacional. México: Siglo XXI.

(1988). Derecho indígena y derechos humanos en américa latina. México: IIDH Instituto Interamericano de Derechos HumanosEl Colegio de México.

Touraine, A. (2006). Los movimientos sociales. Revista colombiana de sociología, (27), 255-278.

Vieira, J. (2007). Missionários, Fazendeiros e Índios de Roraima: a Disputa pela Terra- 1777 a 1980. Boa Vista: Universidade Federal de Roraima (UFRR). 